\title{
Clinical manifestations, prognosis, and treat-to-target assessment of pediatric lupus nephritis
}

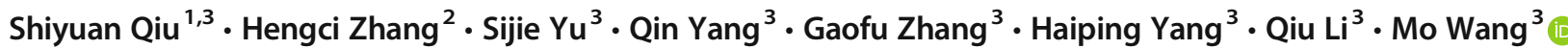

Received: 29 January 2021 / Revised: 9 May 2021 / Accepted: 1 June 2021 / Published online: 11 August 2021

(C) The Author(s) 2021

\begin{abstract}
Background Pediatric lupus nephritis $(\mathrm{pLN})$ is one of the most refractory secondary kidney diseases in childhood. The treat-totarget (T2T) strategy has become the standard treatment for systemic lupus erythematosus (SLE). This study reviewed clinical features, overall remission status, and factors affecting prognosis, to guide pLN management according to T2T strategy.

Methods This single-center retrospective study studied 220 children diagnosed with LN from January 2012 to December 2018, with > 6-month follow-up data on 173 and complete data on 137 patients. Primary outcome was treatment failure (deterioration or no response) at the latest follow-up.

Results The most common pLN manifestation was proteinuria $(81.36 \%)$. Females presented more often with rash $(\mathrm{P}<0.001)$ and alopecia ( $\mathrm{P}=0.026)$ than males. Class IV LN $(33.33 \%)$ was the most common grade on kidney biopsy. Median follow-up was 27.20 months (IQR, 15.78-44.45 months). One-, 3-, and 5-year cumulative overall survival rates were 93.5\%, 87.8\%, and 86.5\%, respectively. The 5-year cumulative kidney survival rate was $97.1 \%$. Regarding initial therapy, efficacy of corticosteroids combined with immunosuppressive agents was significantly better than corticosteroids alone $(\mathrm{P}=0.010)$. Factors with $\mathrm{P}<0.05$ in univariate analysis, including hypoalbuminemia, higher $\mathrm{SCr}$ at diagnosis, lower eGFR at diagnosis, anti-dsDNA positivity, heavy proteinuria, hypertension, nervous-system involvement, treatment non-compliance, and SLEDAI-2K score, were used for logistic regression analysis. Logistic regression analysis showed hypertension $(\mathrm{OR}=0.845, \mathrm{P}=0.011)$, nervous-system involvement $(\mathrm{OR}=4.240, \mathrm{P}=0.005)$, treatment non-compliance $(\mathrm{OR}=6.433, \mathrm{P}=0.001)$, and lower estimated glomerular filtration rate at diagnosis $(\mathrm{OR}=1.020, \mathrm{P}=0.021)$ affected prognosis. At end of follow-up, $34.31 \%$ achieved varying levels of remission, and $8.76 \%$ were in low disease activity state (LDAS).

Conclusions pLN usually presented with proteinuria, and class IV LN was the dominant pathology. Hypertension, nervoussystem involvement, treatment non-compliance, and lower eGFR at diagnosis were independent risk factors for poor prognosis of kidney outcomes. Compared with renal remission rate and cumulative overall survival rate, the proportion of targets achieved was not ideal, suggesting T2T strategy should be used to guide pLN management.
\end{abstract}

Key words Systemic lupus erythematosus $\cdot$ Lupus nephritis $\cdot$ Children $\cdot$ Prognosis

Shiyuan Qiu and Hengci Zhang contributed equally to this work.

Shiyuan Qiu and Hengci Zhang are co-first authors.

Mo Wang

wangmo_cqmu@163.com

Shiyuan Qiu

qiushiyuan@vip.qq.com

Hengci Zhang

zhc5300@126.com

1 Pediatric Internal Medicine Department, Chongqing You You Baobei Women's and Children's Hospital, Chongqing, China
Guizhou Medical University, Guiyang, China

3 Department of Nephrology, Ministry of Education Key Laboratory of Child Development and Disorders, National Clinical Research Center for Child Health and Disorders, China International Science and Technology Cooperation Base of Child Development and Critical Disorders, Children's Hospital of Chongqing Medical University, Chongqing Key Laboratory of Pediatrics, Chongqing, China 


\section{Introduction}

Systemic lupus erythematosus (SLE) is a chronic autoimmune disease, and approximately $20 \%$ of cases occur in childhood [1]. The disease manifestations of pediatric SLE (pSLE) are often more serious, especially for multiple organ functions such as those of the renal, nervous, and circulatory systems [2]. As one of the most common complications of SLE, lupus nephritis (LN) is also one of the most common causes of secondary glomerulonephritis affecting the long-term prognosis of children. LN has various clinical manifestations and pathological types in children, varying from mild hematuria or proteinuria to nephrotic syndrome and kidney failure, which brings difficulties in clinical diagnosis and treatment of pLN. In addition, the high disease activity of SLE and the toxicity related to long-term use of corticosteroids and immunosuppressive agents cause serious damage to the body. $\mathrm{Wu}$ et al. showed that infection and neuropsychiatric lupus (NPL) became the main causes of adult death in SLE [3]. Therefore, treatment in LN should not only focus on renal remission but also aim at controlling systemic disease activity, preventing organ damage, and minimizing comorbidities and drug toxicity. To control disease activity, improve health-related quality of life (HRQoL), and reduce morbidity and mortality, the treat-to-target (T2T) strategy has been proposed in the treatment of SLE since 2014 by the multidisciplinary international task force [4]. Consensus treatment target definitions have been developed and investigated in several adult SLE cohorts $[5,6]$. Several possible targets of the T2T strategy include varying levels of remission and low disease activity state (LDAS). Remission would be the main target, but LDAS could be an acceptable alternative when remission is not achievable. Over the last few years, the T2T strategy has appeared to be effective for preventing damage and improving survival in several cohort studies of adult SLE. However, the T2T strategy has not been applied in the field of pediatrics.

Here, we retrospectively analyzed and conducted prognostic follow-up on the clinical data of 220 children with LN. We summarized their clinical manifestations and renal pathological characteristics, and explored the associated factors for prognosis, to improve the prognosis for future cases of $\mathrm{LN}$. Besides, referring to the proposed targets of adult SLE, we evaluated overall remission in these children to understand their current prognosis and help manage pSLE based on the T2T strategy.

\section{Patients and methods}

\section{Patients}

Patients in this study were 220 children who were hospitalized at the Children's Hospital of Chongqing Medical University,
Chongqing, China, from January 2012 to December 2018. All were diagnosed with SLE and LN at $\leq 18$ years of age. The criteria of SLE were based on the American College of Rheumatology (ACR) classification (2012) [7]. LN was diagnosed according to the following criteria [8]: proteinuria $>150$ $\mathrm{mg} / 24 \mathrm{~h}$, or qualitative urine protein positive for three times per week, or urine protein/urinary creatinine $>0.2 \mathrm{mg} / \mathrm{mg}$, or abnormal urine microalbumin for three times per week; hematuria > $5 \mathrm{RBC} / \mathrm{hpf}$; abnormal function of glomerulus and (or) renal tubules; abnormal kidney biopsy consistent with pathological changes of LN. Kidney biopsy was most highly recommended in LN children with these following characteristics: increasing serum creatinine without compelling alternative causes; proteinuria of $\geq 1.0 \mathrm{~g} / 24 \mathrm{~h}$; proteinuria $\geq 0.5 \mathrm{~g} / 24 \mathrm{~h}$ plus hematuria, defined as $\geq 5 \mathrm{RBC} / \mathrm{hpf}$; proteinuria $\geq 0.5$ $\mathrm{g} / 24 \mathrm{~h}$ plus cellular casts.

The study design is shown in Fig. 1.

\section{Clinical data collection}

Clinical data of children with $\mathrm{LN}$ were collected retrospectively, including main clinical manifestations and laboratory results. The estimated glomerular filtration rate (eGFR) was calculated using the Schwartz formula [9]. We scored SLE activity per the Systemic Lupus Erythematosus Disease Activity Index 2000 (SLEDAI-2K) [10]. LN was pathologically classified according to the International Society of Nephrology/Renal Pathology Society (ISN/RPS) classification (2003) [11]. The activity index (AI) and chronicity index (CI) of each patient were scored per the semi-quantitative scoring method of the National Institutes of Health (NIH) [12].

\section{Definition}

The definitions of the main clinical manifestations, renal relapse, kidney insufficiency, kidney failure, and treatment noncompliance are shown in Table 1. According to the response criteria of ACR [13], we defined four categories of renal outcomes; the details are also shown in Table 1. Based on the T2T strategy [14], the definitions of outcomes of SLE are shown in Table 2.

\section{Statistical analysis}

We statistically analyzed all data using SPSS software version 25.0 (IBM Corp., Armonk, NY, USA). Continuous variables are presented as mean with standard deviation (mean $\pm \mathrm{SD}$ ) or median with interquartile range (IQR). Categorical variables are presented as frequencies and percentages $(\mathrm{n}(\%))$. We used Student's $t$-test, analysis of variance (ANOVA), the MannWhitney $U$ test, and the Kruskal-Wallis $H$ test for comparing continuous variables. Categorical variables were analyzed 


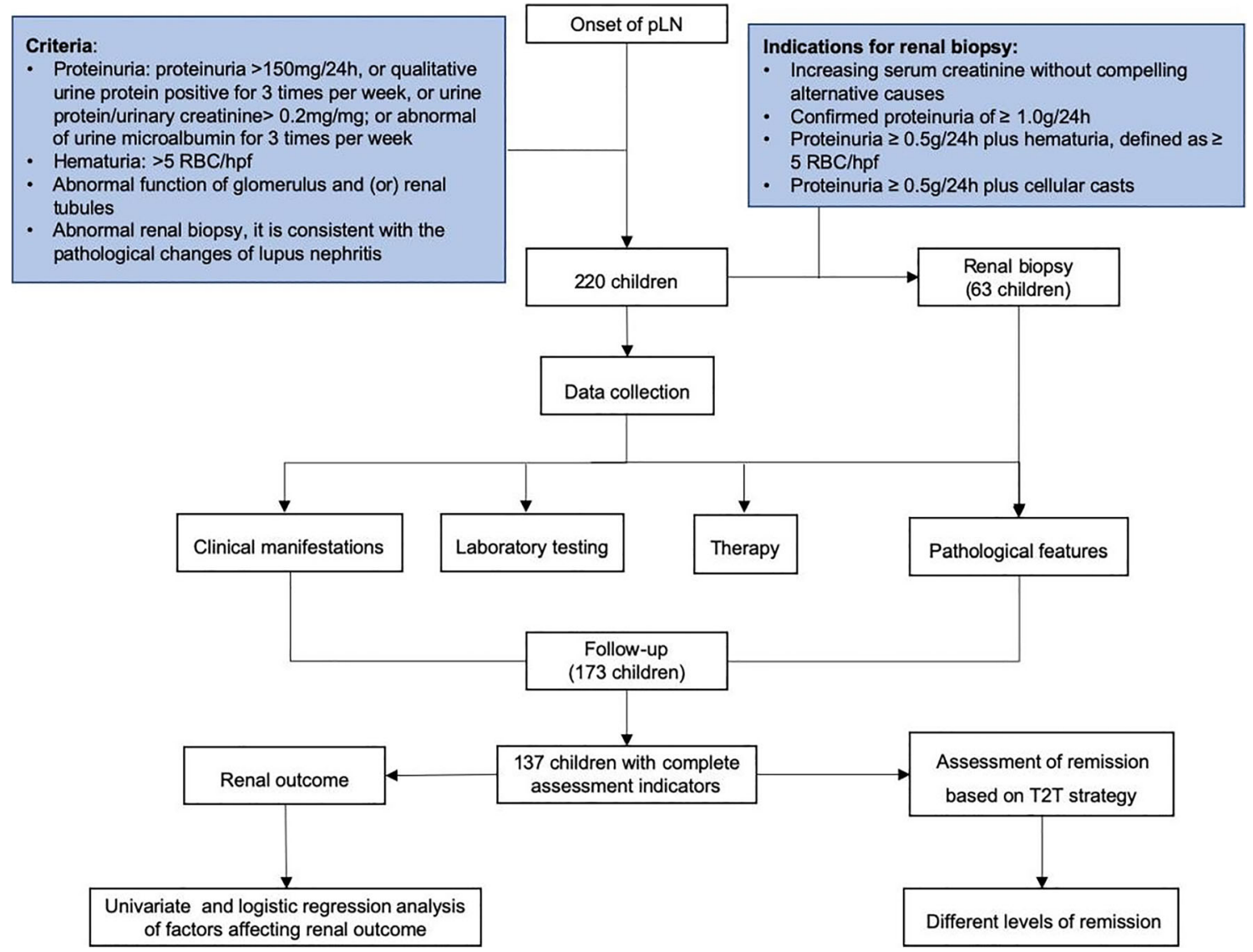

Fig. 1 The study design

using the chi-square or Fisher's exact test. Multifactorial analysis of influencing factors was performed using logistic regression analysis. Kaplan-Meier (KM) analysis was used for survival analysis. Comparisons were performed between groups using the log-rank test. Data were examined at the 95\% confidence level, and $\mathrm{P}$ value $<0.05$ was considered statistically significant. Figures were created with GraphPad Prism 8.

\section{Results}

\section{Clinical and laboratory characteristics}

Of the 220 children with LN included in this study, 50 were males $(22.73 \%)$ and 170 were females $(77.27 \%)$, with a male:female ratio of 1:3.4. The mean age at diagnosis was $10.94 \pm 2.49$ years (minimum, 3.25 years; maximum, 17.00 years). Median disease duration from onset to diagnosis was 1.00 month (IQR 0.40-2.00 months; minimum, 1 day; maximum, 2 years). The main clinical manifestations and laboratory indicators of children with $\mathrm{LN}$ at diagnosis are shown in Supplementary Tables 1, 2, and 3. The most common manifestation was proteinuria $(81.36 \%)$. The median proteinuria was $1.13 \mathrm{~g} /$ day (IQR 0.33-2.41g/day). Among those children with proteinuria, $80(44.69 \%, 80 / 179)$ had nephroticrange proteinuria. Kidney insufficiency was observed in 51 (23.18\%) children at diagnosis. Of initial non-renal manifestations, fever $(65.45 \%)$ and rash $(60.46 \%)$ were the most common. Females presented more often with rash $(\mathrm{P}<0.001)$ and alopecia $(P=0.026)$ than males. Antinuclear antibodies (ANA) were detected in nearly all patients (99.09\%), followed by anti-double-stranded DNA (anti-dsDNA) antibodies $(81.36 \%)$ and anti-single-stranded DNA (anti-ssDNA) antibodies $(78.18 \%)$.

\section{Pathological characteristics}

In this study, a total of 65 children met the indications and willingly underwent kidney biopsy. Two cases were not classified due to limited materials. The distribution and percentage of pathological types in this group are shown in Supplementary Fig. 1. Class IV LN was the most common (21 cases, $33.33 \%)$. There are 27 cases $(42.86 \%)$ of class V LN, including 10 cases of pure class V. No class VI LN was found among the children in this study. 
Table 1 Definitions of clinical manifestations and renal outcomes of SLE

\begin{tabular}{|c|c|}
\hline Item & Definition \\
\hline \multicolumn{2}{|l|}{ Manifestation } \\
\hline Fever & $\geq 38^{\circ} \mathrm{C}$ (except for fever caused by infection) \\
\hline Hypertension & $\begin{array}{l}\text { The systolic blood pressure and (or) diastolic blood pressure are greater than or equal } \\
\text { to the 95th percentile of the blood pressure of children of the same sex, age, and height }\end{array}$ \\
\hline Leukopenia & Peripheral blood white blood cell count $<4 \times 10^{9} / \mathrm{L}$ \\
\hline Thrombocytopenia & Peripheral blood platelet count $<100 \times 10^{9} / \mathrm{L}$ \\
\hline Anemia & Peripheral blood hemoglobin $<110 \mathrm{~g} / \mathrm{L}$ \\
\hline Liver function damage & Doubling of alanine aminotransferase and (or) aspartate aminotransferase compared with the reference value \\
\hline Hypoproteinemia & Serum albumin $<25 \mathrm{~g} / \mathrm{L}$ \\
\hline Oliguria & Daily urination volume of school-age children is $<400 \mathrm{~mL} / \mathrm{m}^{2}$, preschool children is $<300 \mathrm{~mL} / \mathrm{m}^{2}$ \\
\hline Nephrotic proteinuria & Proteinuria $\geq 50 \mathrm{mg} / \mathrm{kg} /$ day \\
\hline Non-nephrotic proteinuria & Proteinuria between $0.15 \mathrm{~g} /$ day and $50 \mathrm{mg} / \mathrm{kg} /$ day \\
\hline Renal relapse & $\begin{array}{l}\text { Includes a proteinuric relapse (a persistent urine protein }>0.15 \mathrm{~g} / \text { day after a complete remission or } \\
\text { a doubling of proteinuria which is more than } 1 \mathrm{~g} / \text { day after a partial remission) and a nephritic } \\
\text { relapse ( }>25 \% \text { elevation in serum creatinine associated with increased urinary sediment). }\end{array}$ \\
\hline Renal insufficiency & serum creatinine $>1.2 \mathrm{mg} / \mathrm{dL}$ and creatinine clearance lower than $75 \mathrm{~mL} / \mathrm{min}$ \\
\hline CKD stage 5 & eGFR $<15 \mathrm{~mL} / \mathrm{min} / 1.73 \mathrm{~m}^{2}$ for 3 months or entering maintenance dialysis \\
\hline Treatment non-compliance & $\begin{array}{l}\text { failure to follow the doctor's prescription or stop the medication during treatment, or fail to be } \\
\text { hospitalized for regular treatment according to the plan }\end{array}$ \\
\hline \multicolumn{2}{|l|}{ Renal outcomes of LN } \\
\hline Complete remission (CR) & $\begin{array}{l}\text { (1) eGFR of } \geq 90 \mathrm{~mL} / \mathrm{min} / 1.73 \mathrm{~m}^{2} \text {; (2) proteinuria is }<0.15 \mathrm{~g} / \text { day or uPCR is }<0.2 \text {; (3) inactive } \\
\text { sediment (defined as } \leq 5 \mathrm{RBCs} / \mathrm{hpf}, \leq 5 \mathrm{WBCs} / \mathrm{hpf} \text { and no cellular casts) }\end{array}$ \\
\hline Partial remission $(\mathrm{PR})$ & $\begin{array}{l}\text { (1) eGFR of }<90 \mathrm{~mL} / \mathrm{min} / 1.73 \mathrm{~m}^{2}, 25 \% \text { increase if baseline eGFR is abnormal, or stable value } \\
\text { if normal at baseline; (2) at least } 50 \% \text { reduction in urinary protein, uPCR is } 0.2-2.0\end{array}$ \\
\hline No remission (NR) & Stable values for the eGFR or urinary protein \\
\hline Deterioration & (1) $25 \%$ decline in estimated GFR or ESRD; $100 \%$ increase in the uPCR; (2) death \\
\hline
\end{tabular}

$e G F R$, estimated glomerular filtration rate; $h p f$, high-power field; $R B C$, red blood cell; $W B C$, white blood cell; $u P C R$, urinary protein: creatinine ratio; $E S R D$, end-stage renal disease

These children were divided into two groups by renal outcome at the end of follow-up: a remission group including CR and PR, and a failure group including NR and deterioration

We compared the main laboratory indices at diagnosis of children with class III LN (including class III+V), class IV LN (including class $\mathrm{IV}+\mathrm{V}$ ), and pure class $\mathrm{V} \mathrm{LN}$. As shown in Supplementary Table 4, we found significant differences in quantitative levels of 24-h urine proteins (24hUPs), eGFRs, and AI values among the three groups of children. After multiple comparisons of post hoc tests, quantitative levels of 24hUPs were significantly higher in children with class IV $\mathrm{LN}$ than in those with class III LN $(Z=2.579 ; \mathrm{P}=0.010)$, while no significant difference was found between class III LN and pure class V LN children or between class IV LN and pure class V LN children (Supplementary Fig. 2a). The eGFR of class III LN and class IV LN was significantly lower than those of pure class $\mathrm{V} \mathrm{LN}(\mathrm{P}=0.016, \mathrm{P}<0.001$, respectively), while no significant difference in eGFR was found between class III LN and class IV LN children (Supplementary Fig. $2 b)$. The AI of class IV LN children was significantly higher than that of class III LN children $(\mathrm{P}<0.001)$.

\section{Initial therapy}

As a retrospective case analysis, the treatment strategies were based on the ACR guidelines [15], and no specific treatment strategies were set for this study. In initial therapy, all children in the cohort were treated with an induction regimen of corticosteroids or corticosteroids combined immunosuppressants, primarily cyclophosphamide (CYC), or mycophenolate (MMF), and hydroxychloroquine as the adjunctive treatment. No patients received a combination of CYC and MMF in their initial treatment. Based on the retrospective collection of data, the children were grouped according to whether they received CYC or MMF as induction treatment to compare the efficacy of CYC and MMF. We compared the main indicators at the beginning of the initial therapy, the end of the initial therapy, and the end of follow-up in the two groups. There was no significant difference in $24 \mathrm{hUP}$, serum creatinine ( $\mathrm{SCr}$ ), complement (C)3, C4, anti-dsDNA antibodies, SLEDAI-2K 
Table 2 Definition of proposed targets (T2T) in SLE

\begin{tabular}{llllll}
\hline & $\begin{array}{l}\text { Complete remission } \\
\text { off therapy }\end{array}$ & $\begin{array}{l}\text { Complete remission } \\
\text { on therapy }\end{array}$ & $\begin{array}{l}\text { Clinical remission } \\
\text { off therapy }\end{array}$ & $\begin{array}{l}\text { Clinical remission } \\
\text { on therapy }\end{array}$ & LDAS \\
\hline Clinical activity & No & No & No & No & Yes, but global SLEDAI $\leq 4$ \\
Serological activity & No & No & Yes & Yes & Yes, but global SLEDAI $\leq 4$ \\
Prednisone & No & $\leq 5 \mathrm{mg} /$ day & No & $\leq 5 \mathrm{mg} /$ day & $\leq 7.5 \mathrm{mg} /$ day \\
Immunosuppressive drugs & No & Yes & No & Yes & Yes \\
Antimalarials & Yes & Yes & Yes & Yes & Yes \\
\hline
\end{tabular}

$L D A S$, low disease activity status

Remission included complete remission off therapy, complete remission on therapy, clinical remission off therapy, and clinical remission on therapy

score, or the rate of remission and LDAS between the CYC and MMF groups (Table 3).

\section{Follow-ups and prognosis}

As of the follow-up endpoint (December 2019), 173 out of 220 LN children had been followed up and 47 cases were lost to follow-up. The overall follow-up rate of our patients was $78.64 \%$ (173/220). The median follow-up duration was 27.20 months (IQR, 15.78-44.45 months), with the shortest 6 months and the longest 81 months.

Death was used as the end event of the survival status. A total of 20 children died during this study, including 8 males and 12 females, with a mortality rate of $11.56 \%$ (20/173). According to KM analysis, 12-month (1-year), 36-month (3year), and 60-month (5-year) cumulative overall survival (OS) rates were $93.5 \%, 87.8 \%$, and $86.5 \%$, respectively (Fig. 2). The cumulative survival rate of males was lower than that of females, showing a significant difference in log-rank analysis $(\mathrm{P}=0.037)$. Analysis of causes of death in the 20 deceased children showed that infection (10 cases, 50\%) was the leading cause of death in all cases, followed by cerebral hemorrhage ( 4 cases, $20.00 \%$ ), cerebral hernia ( 2 cases, $10.00 \%$ ), interstitial lung disease ( 2 cases, $10.00 \%)$, uremia ( 1 case, $5.00 \%$ ), and lupus cardiomyopathy ( 1 case, $5.00 \%$ ).

\section{Renal outcomes}

Among the 173 children we followed up, 137 children had complete assessment indicators for the renal outcomes (Table 1), whose clinical manifestations were not significantly different from those of the overall population (Supplementary Table 1). The renal outcomes of the 137 children were as follows (Fig. 3). We observed complete remission in 17 cases (12.41\%), partial remission in 81 cases $(59.12 \%)$, no remission in 29 cases (21.17\%), and deterioration in 10 cases $(7.30 \%)$ at the end of the initial therapy, with a renal remission rate of $71.53 \%$. At the same time, 23 children had renal relapses after complete or partial remission, with a renal relapse rate of $23.47 \%$ (23/98). At the end of follow-up, we observed complete remission in 23 cases
(16.79\%), partial remission in 66 cases $(48.18 \%)$, no remission in 22 cases $(16.06 \%)$, and deterioration in 26 cases $(18.98 \%)$, with a total remission rate of $64.96 \%$. At the end of follow-up, two children were observed with chronic kidney disease (CKD) stage 5 independently at the 18th and 47th months of disease duration. $\mathrm{KM}$ analysis showed that the 5-year cumulative renal survival rate was $97.1 \%$.

\section{Risk factors for poor prognosis of renal outcomes}

We divided these 137 children into two groups by renal outcomes at the end of follow-up: a remission group including CR and PR, and a failure group including NR and deterioration. We performed univariate analysis to compare demographic data, clinical manifestations, main laboratory indicators, and therapy between the two groups to analyze the risk factors leading to poor prognosis of kidney injury. The results showed that hypoalbuminemia, anti-dsDNA positivity, nephrotic-range proteinuria, hypertension, nervous-system involvement, SLEDAI-2K score, $\mathrm{SCr}$, eGFR, and treatment compliance were significantly different between the two groups of children with $\mathrm{LN}(\mathrm{P}<0.05)$. We found significant differences in treatment plan during the induction period and in treatment compliance between the two groups of children with LN $(\mathrm{P}<0.05)$. Further multiple-comparison results showed that the remission rate of children receiving $\mathrm{CYC}$ was significantly higher than that of children receiving corticosteroid treatment alone $\left(\chi^{2}=7.982 ; \mathrm{P}=0.010\right)$. No significant difference in induction remission rate was found between children in the CYC and the MMF groups $\left(\chi^{2}=0.808 ; \mathrm{P}=0.369\right)$. Univariate analysis of renal pathological indicators in LN children undergoing kidney biopsy showed a significant difference in AI between the two groups $(Z=2.445 ; \mathrm{P}=0.014)$ (Supplementary Table 5).

\section{Multivariate regression analysis of factors for poor prognosis of renal outcomes}

Factors with $\mathrm{P}<0.05$ in univariate analysis, including hypoalbuminemia, higher $\mathrm{SCr}$ at diagnosis, lower eGFR at diagnosis, antidsDNA positivity, heavy proteinuria, hypertension, nervous- 
Table 3 Laboratory parameters in $\mathrm{CYC}$ and MMF groups for $\mathrm{LN}$ initial therapy

\begin{tabular}{|c|c|c|c|}
\hline Parameters & CYC $(n=104)$ & $\operatorname{MMF}(\mathrm{n}=20)$ & $\mathrm{P}$ value \\
\hline \multicolumn{4}{|l|}{ Baseline } \\
\hline 24hUP (g/day) & $1.77(0.82-2.97)$ & $1.47(1.02-2.95)$ & 0.597 \\
\hline $\operatorname{Scr}(\mu \mathrm{moI} / \mathrm{L})$ & $56.00(40.70-94.65)$ & $45.50(38.00-69.05)$ & 0.354 \\
\hline C3 (g/L) & $0.28(0.17-0.42)$ & $0.29(0.19-0.47)$ & 0.773 \\
\hline $\mathrm{C} 4(\mathrm{~g} / \mathrm{L})$ & $0.05(0.02-0.08)$ & $0.07(0.02-0.12)$ & 0.247 \\
\hline Anti-dsDNA (+) & $84(80.77)$ & $15(75.00)$ & 0.556 \\
\hline SLEDAI-2K & $15.16 \pm 4.63$ & $13.80 \pm 6.83$ & 0.401 \\
\hline \multicolumn{4}{|l|}{ End of initial therapy } \\
\hline 24hUP (g/day) & $0.98(0.69-1.60)$ & $0.91(0.32-1.57)$ & 0.197 \\
\hline $\mathrm{SCr}(\mu \mathrm{moI} / \mathrm{L})$ & $49.30(41.00-58.25)$ & $43.05(36.10-52.50)$ & 0.100 \\
\hline C3 (g/L) & $0.76(0.55-0.92)$ & $0.74(0.59-0.88)$ & 0.758 \\
\hline $\mathrm{C} 4(\mathrm{~g} / \mathrm{L})$ & $0.16(0.11-0.19)$ & $0.18(0.09-0.21)$ & 0.695 \\
\hline Anti-dsDNA (+) & $51(49.04)$ & $11(55.00)$ & 0.625 \\
\hline SLEDAI-2K & $5.97 \pm 3.88$ & $6.90 \pm 3.46$ & 0.321 \\
\hline Renal remission $^{\mathrm{a}}$ & $79(75.96)$ & $13(65.00)$ & 0.305 \\
\hline \multicolumn{4}{|l|}{ End of follow-up } \\
\hline 24hUP (g/day) & $0.69(0.28-1.90)$ & $0.33(0.19-1.30)$ & 0.180 \\
\hline $\mathrm{SCr}(\mu \mathrm{mol} / \mathrm{L})$ & $47.85(39.35-55.95)$ & $44.50(38.00-55.00)$ & 0.482 \\
\hline C3 (g/L) & $0.74(0.63-0.89)$ & $0.68(0.45-0.81)$ & 0.153 \\
\hline $\mathrm{C} 4(\mathrm{~g} / \mathrm{L})$ & $0.16(0.11-0.21)$ & $0.13(0.08-0.18)$ & 0.195 \\
\hline Anti-dsDNA (+) & $35(33.65)$ & $9(45.00)$ & 0.331 \\
\hline SLEDAI-2K & $5.10 \pm 4.71$ & $6.05 \pm 5.24$ & 0.417 \\
\hline Renal remission $^{\mathrm{a}}$ & 73 (70.19) & $12(60.00)$ & 0.369 \\
\hline Overall remission ${ }^{\mathrm{b}}$ & $41(39.42)$ & $5(25.00)$ & 0.221 \\
\hline LDAS (excluding remission) & $9(8.66)$ & $3(15.00)$ & 0.408 \\
\hline
\end{tabular}

$24 h U P, 24$-h urinary protein; $S C r$, serum creatinine; $C 3$, complement $3 ; C 4$, complement 4 ; anti-dsDNA, antidouble-stranded DNA; SLEDAI-2K, systemic lupus erythematosus disease activity index 2000; LDAS, low disease activity status

${ }^{\text {a }}$ Including complete remission and partial remission of renal outcomes

${ }^{\mathrm{b}}$ Including complete remission off/on therapy and clinical remission off/on therapy

system involvement, treatment non-compliance, and SLEDAI$2 \mathrm{~K}$ score, were included in the logistic regression analysis (Table 4). The results showed that hypertension, nervoussystem involvement, treatment non-compliance, and lower eGFR at diagnosis were independent risk factors affecting the prognosis of renal outcomes.

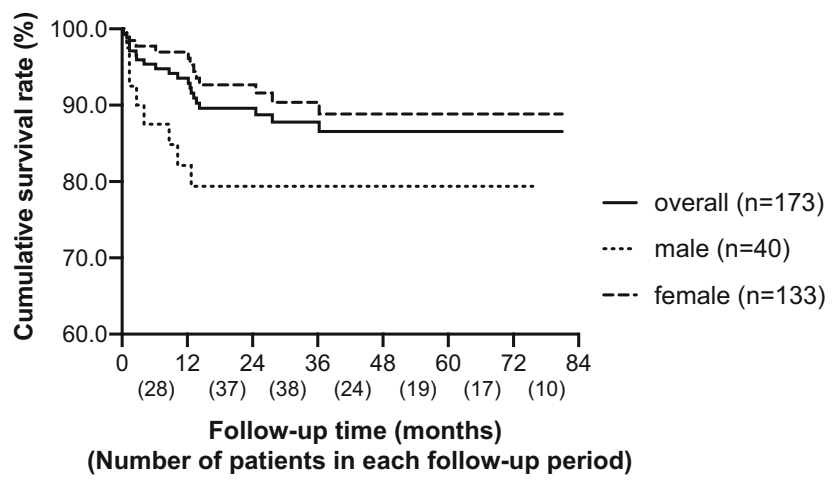

Fig. 2 Survival analysis of LN

\section{Assessment of overall treatment targets}

Based on the T2T strategy, this study evaluated the conditions of 137 children at the end of follow-up (Table 5). We found that 47 children $(34.31 \%)$ achieved varying levels of remission. Of these, 5 (3.65\%) achieved complete remission off therapy, 19 (13.87\%) achieved complete remission on therapy, $1(0.73 \%)$ had clinical remission off therapy, and 22 $(16.06 \%)$ had clinical remission on therapy. Twelve (8.76\%) achieved LDAS. Seventy-eight (56.93\%) of these children did not achieve any level of remission or LDAS.

\section{Discussion}

PSLE is an autoimmune disease that causes multi-system damage and LN is one of its most important complications. Childhood LN is often more serious than $\mathrm{LN}$ onset in later adulthood [16]. Therefore, early diagnosis, timely treatment, 
Fig. 3 Outcome of 137 LN children at the end of initial therapy and the end of follow-up

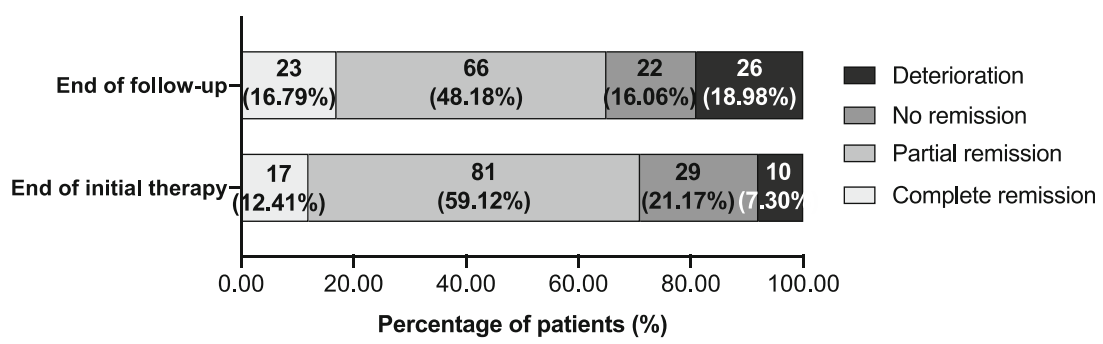

and reasonable management are essential to improving the prognosis of children with $\mathrm{LN}$.

In our study, the epidemiological characteristics and clinical manifestations were similar to previous reports. The initial manifestation of kidney involvement was mainly proteinuria. Of initial non-renal manifestations, fever and rash were the most common. Compared with adult patients, symptoms such as oral ulcers and alopecia in pediatric patients were relatively rare. Also, females presented more often with rash and alopecia than males in our study. Compared with females, males often have atypical clinical manifestations and heavily rely on examinations for diagnosis.

Few children with LN in our center had neuropsychiatric symptoms. However, multivariate regression analysis showed that nervous-system involvement was an independent risk factor affecting prognosis in pSLE, and was also the secondleading cause of death in this study (cerebral hemorrhage and cerebral hernia). Children with NPL are sometimes ignored in the early stage due to mild or asymptomatic clinical presentation, leading them to be misdiagnosed or undiagnosed. However, once severe symptoms such as disturbance of consciousness, epilepsy, and brain herniation occur, the disability and fatality rates of these patients are relatively high. Therefore, it is necessary to be vigilant in clinical practice. Electroencephalography, cerebrospinal fluid tests, head

Table 4 Logistic regression analysis of risk factors leading poor prognosis of $137 \mathrm{LN}$ children

\begin{tabular}{llll}
\hline Influencing factors & P value & OR & $95 \% \mathrm{CI}$ \\
\hline Hypoproteinemia & 0.845 & 0.851 & $0.169-4.277$ \\
SCr at diagnosis & 0.163 & 1.012 & $0.995-1.029$ \\
eGFR at diagnosis & 0.021 & 1.020 & $1.003-1.037$ \\
Anti-dsDNA (+) & 0.140 & 2.567 & $0.735-8.964$ \\
Nephrotic-range proteinuria & 0.324 & 2.272 & $0.445-11.590$ \\
Hypertension & 0.011 & 3.448 & $1.326-8.970$ \\
Nervous-system involvement & 0.005 & 4.240 & $1.531-11.739$ \\
Treatment non-compliance & 0.001 & 6.433 & $2.228-18.578$ \\
SLEDAI-2K & 0.560 & 0.974 & $0.892-1.064$ \\
\hline
\end{tabular}

$S C r$, serum creatinine; $e G F R$, estimated glomerular filtration rate; antidSDNA, anti-double-stranded DNA; SLEDAI-2K, Systemic Lupus Erythematosus Disease Activity Index 2000 imaging, and other auxiliary examinations should be used to comprehensively evaluate children with SLE.

Kidney biopsy data in this study showed that class IV LN was the most common pathological type. These findings were consistent with those of another study [17]. Clinical manifestations of LN also had a certain relationship to the pathological type of LN. For example, urine protein level was significantly higher in class IV LN than in class III LN, and kidney function was better in pure class $\mathrm{V}$ LN than in proliferative LN. However, the clinical manifestations of children with LN were not completely consistent with the pathological types of LN. Biopsies of some children with mild proteinuria confirmed them to have class IV LN, with relatively high AI and CI scores. In the course of disease progression, the pathological type of LN can also change. Repeat kidney biopsy is also recommended in some cases, such as worsening or refractoriness to treatment. In this study, the data showed that one patient underwent kidney biopsy again after an interval of 2 years, and the patient's pathological type changed from class V LN to class III+V LN, with CI score reaching 5 points. So when children with SLE have evidence of kidney damage, a timely kidney biopsy is recommended to clarify the pathological type and provide reasonable treatment in time.

Consistent with the previous study by Smith et al. [18], regarding regimens for initial therapy, no significant differences in renal remission were found between the CYC and MMF groups at the end of the initial therapy. Notably, treatment non-compliance was an independent risk factor affecting the prognosis of LN children. During follow-up and while communicating with parents of LN children, we learned that

Table 5 Various types of remission at end of follow-up in $137 \mathrm{LN}$ children

\begin{tabular}{lll}
\hline Targets & $\mathrm{n}$ & Percentage (\%) \\
\hline Remission & 47 & 34.31 \\
Complete remission off therapy & 5 & 3.65 \\
Complete remission on therapy & 19 & 13.87 \\
Clinical remission off therapy & 1 & 0.73 \\
Clinical remission on therapy & 22 & 16.06 \\
LDAS (excluding remission) & 12 & 8.76 \\
\hline
\end{tabular}

$L D A S$, low disease activity status 
some children failed to follow medical advice for treatment due to insufficient understanding of the disease or emotional disorders. HRQoL has attracted more and more attention and is usually overlooked in the management of SLE. Donnelly et al. showed that emotional symptoms such as anxiety and depression predict the decline of HRQoL in children with SLE [19]. Therefore, in clinical treatment, we must provide not only health education for the parents of these children but also appropriate psychological counseling for the children themselves, strengthen their understanding of the disease, and treat their psychiatric disorders.

Vachvanichsanong et al. reported that sepsis was the leading cause of death in children with LN in Thailand [20]. As in most reports, infection was also the primary cause of death in children with LN in this study (50.00\%). Therefore, for children with infections, clinical pathogenic examinations should be completed in a timely fashion, and antibiotics should be used rationally to control the infections.

This study showed that at the end of the follow-up, the renal remission rate $(64.97 \%)$ and cumulative overall survival rate $(86.50 \%, 5$-year) were relatively higher. However, assessing the achievement of targets with T2T strategy, only $34.31 \%$ of children achieved varying levels of remission, and $8.76 \%$ of children achieved LDAS. Compared with studies of adult SLE [21, 22], these proportions were lower. Franklyn et al. reported that $88.5 \%$ of 191 patients in their cohort achieved LDAS at least once, and the cumulative duration of LDAS was $41 \%$ of the total period of observation [14]. Compared with adults, children are more active in SLE and receive more intensive immunosuppressive therapy. Even if the disease is in remission, it is mostly clinical remission on therapy, meaning that long-term use of steroids and immunosuppressants is toxic and accumulates more organ damage over time. Therefore, pediatric nephrologists also need to pay attention to the systemic damage of SLE in the treatment of pLN and try to use the T2T strategy to guide the management of these children. It is necessary to consider other optimized treatment programs to improve the prognosis of children with LN. Emerging therapeutic antibodies have become an alternative and have been extensively studied for the treatment of SLE, such as rituximab and belimumab [23, 24]. T2T is currently the most advocated strategy in the management of SLE. However, as yet there is a lack of long-term observation of organ damage and outcomes based on the T2T strategy in children. The specific targets of pSLE have not yet been defined. A recent study [25] of pSLE parents by interviews showed that the concept of T2T was acceptable to families. Most families were reluctant to tolerate ongoing symptoms, and remission was a more attractive treatment target for them than LDAS. Therefore, this requires further large-sample, multi-center, and even prospective studies to develop the definition of remission that would be acceptable to families. The precise minimum doses of immunosuppressive drugs and corticosteroids allowed should also be defined for remission or LDAS.

Several limitations of this study should be mentioned. We retrospectively collected and analyzed data in a single center for pSLE patients with kidney involvement. We have identified several risk factors that affect the renal prognosis, which is only part of the risk factors for poor prognosis of pSLE since treatment of SLE is the integrated management of multiple organ injuries. We also pay attention to the difference between renal prognosis and the targets of T2T. However, due to the relatively small samples from a single-center study, it is difficult to conduct statistical analysis based on T2T target groupings. Besides, as a retrospective study, we only assessed the overall remission of children with $\mathrm{LN}$ at the end of the followup, so we could not accurately confirm the time to achieve each target and the duration of remission without prospective application of the T2T strategy in the management of pLN in this cohort. Our team plans to continue this study and incorporate multi-center data, which would hopefully find more predictors for poor prognosis of pSLE, different remissions, and LDAS and confirm the definitions of T2T in pSLE.

In conclusion, this is one of the largest cohort studies of pLN from a single center in China. We summarized the clinical manifestations and analyzed the associated factors for the prognosis of pLN. Further to this, the innovation of this study is that we used the promising T2T strategy to assess the outcomes of these children. Compared with the relatively higher renal remission rate and cumulative overall survival rate, the proportion of targets (T2T) achieved was not ideal. This suggested that we also need to pay attention to the practice of T2T for pSLE.

Supplementary Information The online version contains supplementary material available at https://doi.org/10.1007/s00467-021-05164-y.

Acknowledgments We thank all physicians who contributed to the data by filling in the patients' medical records and all children and their families.

Availability of data and material Data are available upon request. Code availability Codes are available upon request.

Author contribution Shiyuan Qiu and Hengci Zhang analyzed the clinical data and wrote the manuscript. Sijie Yu and Qin Yang collected the clinical data from the patients. Gaofu Zhang, Haiping Yang, and Qiu Li conducted a discussion, and Mo Wang designed and revised the manuscript. All authors read and approved the final manuscript.

Funding This study was financially supported by the central government directs special funds for local science and technology development.

\section{Declarations}

Ethics approval This study complied with the ethical principles of the Helsinki Declaration of the World Medical Association and was approved 
by the ethics committee of the Children's Hospital of Chongqing Medical University (approval number: 93/2020).

Consent to participate Informed consent was obtained from legal guardians.

Consent for publication The participants consented to the submission of the report for publication.

Conflict of interest The authors declare no competing interests.

Open Access This article is licensed under a Creative Commons Attribution 4.0 International License, which permits use, sharing, adaptation, distribution and reproduction in any medium or format, as long as you give appropriate credit to the original author(s) and the source, provide a link to the Creative Commons licence, and indicate if changes were made. The images or other third party material in this article are included in the article's Creative Commons licence, unless indicated otherwise in a credit line to the material. If material is not included in the article's Creative Commons licence and your intended use is not permitted by statutory regulation or exceeds the permitted use, you will need to obtain permission directly from the copyright holder. To view a copy of this licence, visit http://creativecommons.org/licenses/by/4.0/.

\section{References}

1. Kamphuis S, Silverman E (2010) Prevalence and burden of pediatric-onset systemic lupus erythematosus. Nat Rev Rheumatol 6:538-546. https://doi.org/10.1038/nrrheum.2010.121

2. Aggarwal A, Srivastava P (2014) Childhood onset systemic lupus erythematosus: how is it different from adult SLE? Int J Rheum Dis 18:182-191

3. Wu XY, Yang M, Xie YS, Xiao WG, Lin J, Zhou B, Guan X, Luo CN, Che N, Liu XZ, Wang C, Teng JL, Cheng XB, Ye JN, Su YT, Shi H, Yin YF, Liu MR, Sun Y, Hu QY, Zhou ZC, Chi HH, Liu Y, Zhang X, Chen JW, Zhang MJ, Zhao DB, Yang CD, Wu LJ, Liu HL (2019) Causes of death in hospitalized patients with systemic lupus erythematosus: a 10-year multicenter nationwide Chinese cohort. Clin Rheumatol 38:107-115. https://doi.org/10.1007/s10067018-4259-z

4. van Vollenhoven R, Mosca M, Bertsias G, Isenberg D, Kuhn A, Lerstrom K, Aringer M, Bootsma H, Boumpas D, Bruce IN, Cervera R, Clarke A, Costedoat-Chalumeau N, Czirjak L, Derksen R, Dorner T, Gordon C, Graninger W, Houssiau F, Inanc M, Jacobsen S, Jayne D, Jedryka-Goral A, Levitsky A, Levy R, Mariette X, Morand E, Navarra S, Neumann I, Rahman A, Rovensky J, Smolen J, Vasconcelos C, Voskuyl A, Voss A, Zakharova H, Zoma A, Schneider M (2014) Treat-to-target in systemic lupus erythematosus: recommendations from an international task force. Ann Rheum Dis 73:958-967. https://doi.org/10.1136/ annrheumdis-2013-205139

5. Tsang ASMW, Bultink IE, Heslinga M, Voskuyl AE (2017) Both prolonged remission and lupus low disease activity state are associated with reduced damage accrual in systemic lupus erythematosus. Rheumatology (Oxford) 56:121-128. https://doi.org/10.1093/ rheumatology/kew377

6. Petri M, Magder LS (2018) Comparison of remission and lupus low disease activity state in damage prevention in a united states systemic lupus erythematosus cohort. Arthritis Rheum 70:1790-1795. https://doi.org/10.1002/art.40571

7. Petri M, Orbai A, Alarcon G, Gordon C, Merrill JT, Fortin PR, Bruce IN, Isenberg D, Wallace DJ, Nived O, Sturfelt G, Ramsey-
Goldman R, Bae SC, Hanly JG, Sanchez-Guerrero J, Clarke A, Aranow C, Manzi S, Urowitz M, Gladman D, Kalunian K, Costner M, Werth VP, Zoma A, Bernatsky S, Ruiz-Irastorza G, Khamashta MA, Jacobsen S, Buyon JP, Maddison P, Dooley MA, van Vollenhoven RF, Ginzler E, Stoll T, Peschken C, Jorizzo JL, Callen JP, Lim SS, Fessler BJ, Inanc M, Kamen DL, Rahman A, Steinsson K, Franks AG Jr, Sigler L, Hameed S, Fang H, Pham N, Brey R, Weisman MH, McGwin G Jr, Magder LS (2012) Derivation and validation of the systemic lupus international collaborating clinics classification criteria for systemic lupus erythematosus. Arthritis Rheum 64:2677-2686. https://doi.org/10. 1002/art.34473

8. Subspecialty Group of Renal Diseases, the Society of Pediatrics, Chinese Medical Association (2018) Evidence-based guideline on diagnosis and treatment of lupus nephritis (2016). Zhonghua Er Ke Za Zhi 56:88-94. https://doi.org/10.3760/cma.j.issn.0578-1310. 2018.02.003

9. Schwartz G, Munoz A, Schneider M, Mak R, Kaskel F, Warady B, Furth S (2009) New equations to estimate GFR in children with CKD. J Am Soc Nephrol 20:629-637. https://doi.org/10.1681/ ASN.2008030287

10. Gladman D, Ibañez D, Urowitz M (2002) Systemic Lupus Erythematosus Disease Activity Index 2000. J Rheumatol 29: 288-291

11. Weening JJ, D’Agati VD, Schwartz MM, Seshan SV, Alpers CE, Appel GB, Balow JE, Bruijn JA, Cook T, Ferrario F, Fogo AB, Ginzler EM, Hebert L, Hill G, Hill P, Jennette JC, Kong NC, Lesavre P, Lockshin M, Looi LM, Makino H, Moura LA, Nagata M (2004) The classification of glomerulonephritis in systemic lupus erythematosus revisited. Kidney Int 65:521-530. https://doi.org/10. 1111/j.1523-1755.2004.00443.x

12. Austin H, Muenz L, Joyce K, Antonovych T, Kullick M, Klippel J, Decker J, Balow J (1983) Prognostic factors in lupus nephritis. Contribution of renal histologic data. Am J Med 75:382-391. https://doi.org/10.1016/0002-9343(83)90338-8

13. Renal Disease Subcommittee of the American College of Rheumatology Ad Hoc Committee on Systemic Lupus Erythematosus Response Criteria (2006) The American College of Rheumatology response criteria for proliferative and membranous renal disease in systemic lupus erythematosus clinical trials. Arthritis Rheum 54:421-432. https://doi.org/10.1002/art.21625

14. Franklyn K, Lau CS, Navarra SV, Louthrenoo W, Lateef A, Hamijoyo L, Wahono CS, Chen SL, Jin O, Morton S, Hoi A, Huq M, Nikpour M, Morand EF (2016) Definition and initial validation of a lupus low disease activity state (LLDAS). Ann Rheum Dis 75:1615-1621. https://doi.org/10.1136/annrheumdis-2015207726

15. Hahn BH, McMahon MA, Wilkinson A, Wallace WD, Daikh DI, FitzGerald JD, Karpouzas GA, Merrill JT, Wallace DJ, Yazdany J, Ramsey-Goldman R, Singh K, Khalighi M, Choi S-I, Gogia M, Kafaja S, Kamgar M, Lau C, Martin WJ, Parikh S, Peng J, Rastogi A, Chen W, Grossman JM (2012) American College of Rheumatology guidelines for screening, treatment, and management of lupus nephritis. Arthritis Care Res 64:797-808. https:// doi.org/10.1002/acr.21664

16. Sato V, Marques I, Goldenstein PT, Carmo L, Jorge L, Titan S, Barros R, Woronik V (2012) Lupus nephritis is more severe in children and adolescents than in older adults. Lupus 21:978-983. https://doi.org/10.1177/0961203312443421

17. Srivastava P, Abujam B, Misra R, Lawrence A, Agarwal V, Aggarwal A (2016) Outcome of lupus nephritis in childhood onset SLE in North and Central India: single-centre experience over 25 years. Lupus 25:547-557. https://doi.org/10.1177/ 0961203315619031

18. Smith E, Al-Abadi E, Armon K, Bailey K, Ciurtin C, Davidson J, Gardner-Medwin J, Haslam K, Hawley D, Leahy A, Leone V, 
McErlane F, Mewar D, Modgil G, Moots R, Pilkington C, Ramanan A, Rangaraj S, Riley P, Sridhar A, Wilkinson N, Beresford MW, Hedrich CM (2019) Outcomes following mycophenolate mofetil versus cyclophosphamide induction treatment for proliferative juvenile-onset lupus nephritis. Lupus 28:613620. https://doi.org/10.1177/0961203319836712

19. Donnelly C, Cunningham N, Jones J, Ji L, Brunner H, KashikarZuck S (2018) Fatigue and depression predict reduced healthrelated quality of life in childhood-onset lupus. Lupus 27:124133. https://doi.org/10.1177/0961203317716317

20. Vachvanichsanong P, McNeil E, Dissaneewate P (2019) A 30-year retrospective study on causes of death in childhood-onset systemic lupus erythematosus in a tertiary care centre in Southern Thailand. Clin Exp Rheumatol 37:879-884

21. van Vollenhoven R, Voskuyl A, Morand E, Aranow C (2015) Remission in SLE: closing in on the target. Ann Rheum Dis 74: 21032106. https://doi.org/10.1136/annrheumdis-2015-208231

22. Zen M, Iaccarino L, Gatto M, Saccon F, Larosa M, Ghirardello A, Punzi L, Doria A (2018) Lupus low disease activity state is associated with a decrease in damage progression in Caucasian patients with SLE, but overlaps with remission. Ann Rheum Dis 77:104 110. https://doi.org/10.1136/annrheumdis-2017-211613

23. Basu B, Roy B, Babu BG (2017) Efficacy and safety of rituximab in comparison with common induction therapies in pediatric active lupus nephritis. Pediatr Nephrol 32:1013-1021. https://doi.org/10. 1007/s00467-017-3583-x

24. Brunner HI, Abud-Mendoza C, Viola DO, Calvo Penades I, Levy D, Anton J, Calderon JE, Chasnyk VG, Ferrandiz MA, Keltsev V, Paz Gastanaga ME, Shishov M, Boteanu AL, Henrickson M, Bass D, Clark K, Hammer A, Ji BN, Nino A, Roth DA, Struemper H, Wang ML, Martini A, Lovell D, Ruperto N, Paediatric Rheumatology International Trials Organisation (PRINTO) and the Pediatric Rheumatology Collaborative Study Group (PRCSG) (2020) Safety and efficacy of intravenous belimumab in children with systemic lupus erythematosus: results from a randomised, placebo-controlled trial. Ann Rheum Dis 79:1340-1348. https:// doi.org/10.1136/annrheumdis-2020-217101

25. Smith EMD, Gorst SL, Al-Abadi E, Hawley DP, Leone V, Pilkington C, Ramanan AV, Rangaraj S, Sridhar A, Beresford MW, Young B (2021) "It is good to have a target in mind": qualitative views of patients and parents informing a treat to target clinical trial in JSLE. Rheumatology (Oxford). https://doi.org/10. 1093/rheumatology/keab173

Publisher's note Springer Nature remains neutral with regard to jurisdictional claims in published maps and institutional affiliations. 